\title{
International Commodity Taxation under Monopolistic Competition *
}

\author{
Andreas Haufler \\ University of Munich and CESifo \\ Michael Pflüger \\ DIW Berlin and IZA
}

November 2002

\begin{abstract}
We analyze non-cooperative commodity taxation in a two-country trade model characterized by monopolistic competition and international firm and capital mobility. In this setting, taxes in one country affect foreign welfare through the relocation of mobile firms and through changes in the rents accruing to capital owners. With consumption-based taxation, these fiscal externalities exactly offset each other and the non-cooperative tax equilibrium is Pareto efficient. With production-based taxation, however, there are additional externalities on the foreign tax base and the foreign price level which lead non-cooperative tax rates to exceed their Pareto efficient levels.
\end{abstract}

Keywords: tax competition, market imperfections, international trade JEL-Classification: F12, H21, H87

* Paper presented at the Congress of the European Economic Association in Lausanne, at the Congress of the International Institute of Public Finance in Linz and at Humboldt University, Berlin. We thank Michael Burda, Kai Konrad, Pierre Picard, Frank Stähler and Ian Wooton for useful comments and suggestions. Special thanks to an anonymous referee for an exceptionally helpful and detailed report. 


\section{Introduction}

During the last two decades, the fiscal importance of commodity taxes has increased considerably as many OECD countries have adjusted commodity tax rates upward in order to make up for revenue losses caused by income tax reforms. These reforms have emphasized the importance of maintaining national autonomy over the rates of general commodity taxation in order to balance the government budget. This is true even in the European Union (EU), where a minimum value-added tax (VAT) rate of $15 \%$ has been introduced, but further VAT harmonization meets serious opposition from most EU member states. ${ }^{1}$

National autonomy over commodity tax rates raises, however, the possibility that these taxes are used strategically and tax competition results. For this reason the discussion has also stressed the importance of adopting an international tax regime that minimizes the incentives to pursue such beggar-thy-neighbour policies. The issue of choosing a tax principle that maximizes world welfare when countries behave non-cooperatively has been addressed in the literature mostly in a setting of perfect competition and commodity trade only. In the present paper we extend this framework by considering monopolistic competition and international firm mobility, thus linking our analysis to recent work in the international trade literature.

In principle, international commodity trade can be taxed either in the country of consumption (destination principle) or in the country of production (origin principle). Under the destination principle goods leave the exporting country free of tax, whereas under the origin principle commodities are traded at tax-inclusive prices.

Historically, world trade has been taxed under the destination principle and this is still true for the large majority of international transactions today. Two recent developments have, however, begun to undermine the general applicability of this tax scheme. First, regional integration of national markets creates increasing possibilities for consumers to shop in neighbouring jurisdictions, at the tax rates of the exporting country. This issue has been of central importance in the EU, where border controls between member states have been abolished. Cross-border shopping is also of concern at the U.S.-Canadian border and its role is likely to increase in

\footnotetext{
${ }^{1}$ At present, the EU's minimum VAT rate is binding only for Luxembourg.
} 
other parts of the world as regional integration proceeds. Second - and perhaps even more important - is the growth of remote sales through mail-ordering and electronic commerce, which offers new possibilities for consumers to engage in tax arbitrage. ${ }^{2}$ It is clearly recognized both in the European Union and in North America, however, that enforcing destination-based taxes on these purchases entails severe compliance costs for the businesses involved (Keen and Smith 1996, Mikesell 2000). Given these practical shortcomings, the case for the destination principle has been reconsidered in recent years and it has been asked whether the theoretical arguments for this tax scheme vis-a-vis the competing origin principle are sufficiently strong and robust to warrant the additional administrative costs involved.

The choice between the destination and origin principles has been extensively discussed in the literature, but almost all analyses have been carried out in a setting of perfectly competitive product markets. ${ }^{3} \mathrm{~A}$ benchmark result is that the destination and origin principles are equivalent, if either exchange rates or producer prices are fully flexible, and if the commodity tax can be levied on all goods at the same rate (see Lockwood, de Meza and Myles, 1994). Existing value-added taxes, however, have zero or reduced tax rates for important categories of goods and services (e.g. banking and insurance, foodstuff, housing) so that VAT should be more realistically thought of as a selective commodity tax. In this case, tax differentials between countries distort international consumption patterns when taxes are levied under the destination principle, whereas international production patterns are distorted when taxes are levied under the origin principle. By the production efficiency theorem, this establishes a basic argument for consumption-based commodity taxation (e.g. Frenkel, Razin and Sadka 1991). Furthermore, under the origin principle, noncooperative tax policies lead to tax rates being inefficiently low in at least one country when goods produced in the trading countries are perfect substitutes (Mintz and Tulkens 1986). Under the destination principle, in contrast, no fiscal externalities

\footnotetext{
${ }^{2}$ Empirical evidence for the U.S. shows that residents of states with high sales taxes are significantly more likely to buy in the Internet (Goolsbee 2000). For the European Union, Nam, Parsche and Schaden (2001) calculate, on the basis of national accounts statistics, that VAT evasion has increased in eight out of ten selected member states during the time period 1994-1996.

${ }^{3}$ See Lockwood (2001) for a recent and thorough synthesis of the literature on the choice of tax principle and the related issue of tax rate harmonization.
} 
are present when countries are too small to affect world prices. Hence, in this setting the non-cooperative equilibrium under the destination principle Pareto dominates the outcome under the origin principle (Lockwood 2001, Propositions 1 and 2). ${ }^{4}$ In recent years, a few contributions have begun to analyze the choice of commodity tax principle under conditions of imperfect competition, and have questioned the policy case for the destination regime. Using a duopoly model with a homogeneous good traded in an integrated market, Keen and Lahiri (1998) have shown that consumption taxes will be inferior to production taxes in a variety of scenarios under both cooperative and non-cooperative tax setting. One particularly noteworthy result of their analysis (Proposition 6) is that when countries are identical, non-cooperative taxation under the destination principle causes efficiency losses, whereas tax competition under the origin principle yields the first best. Haufler, Schjelderup and Stähler (2002) have introduced transport costs and market segmentation into this model and have shown that the welfare comparison between the two tax regimes becomes ambiguous in this case. For low levels of transport costs the origin principle continues to dominate, but this ranking is turned around in favour of the destination principle when transport costs become sufficiently high.

Lockwood (2001, sec. 4 and 6) sets up a different model of imperfect competition, which combines imperfect substitutability of goods with profit-making firms. As in Keen and Lahiri (1998), firms can export into foreign markets, but are not allowed to relocate abroad. In Lockwood's model, taxes levied under either the destination or the origin principle create international spillovers on the profits of foreign firms. In this setting, a welfare comparison of the Nash equilibria under the two regimes requires simulation methods and yields ambiguous results. Therefore, even though the strong findings of Keen and Lahiri in favour of the origin principle are not confirmed in this framework, a general welfare argument for the destination principle has also not been established so far under conditions of imperfect competition.

\footnotetext{
${ }^{4}$ Some caveats to this conclusion should be mentioned. First, production efficiency may not be desirable from the perspective of world welfare maximization when the trading countries face separate budget constraints and lump-sum transfers between them are excluded (Keen and Wildasin 2000). Second, when large countries engage in tax competition, terms of trade effects are present. Then neither of the two tax principles Pareto dominates the other (Lockwood 1993).
} 
The present paper studies non-cooperative commodity taxation under destination and origin regimes in a framework of monopolistic competition and product differentiation. ${ }^{5}$ This model, and its 'economic geography' extensions, have recently been applied to a number of different policy contexts including industrial policy (Flam and Helpman 1987, Venables 1987), the provision of public infrastructure and regional aid (Martin and Rogers 1995a, 1995b), capital and income tax competition (Andersson and Forslid 1999; Kind, Midelfart Knarvik and Schjelderup 2000; Baldwin and Krugman 2000), environmental tax competition (Pflüger 2001), and the fiscal effects of regional integration (Ludema and Wooton 2000). An important advantage of this model is that it can be extended to allow for the relocation decisions of internationally mobile firms. Furthermore, we are able to derive closed-form solutions for all endogenous variables, making it easy to interpret the results obtained.

A striking result of our analysis is that non-cooperative tax policy under the destination principle achieves the first best, because the fiscal externalities associated with international capital and firm mobility exactly offset each other. A domestic tax rise drives firms to the foreign country and raises foreign welfare by reducing aggregate transport costs. At the same time, however, the tax also reduces the rents that accrue to foreign capital owners. Under the origin principle, these effects are also present but there are additional externalities on the foreign tax base and the foreign price level which lead tax rates to depart from their Pareto optimal levels. Hence, in direct contrast to the results of Keen and Lahiri (1998), the non-cooperative tax equilibrium under the destination regime strictly dominates the tax equilibrium under the origin principle.

The paper is set up as follows. In Section 2 we describe the symmetric monopolistic competition model that underlies our analysis. Section 3 derives the optimal commodity tax rates in the benchmark case where taxes are set cooperatively. Section 4 analyzes non-cooperative commodity taxation under the destination principle and Section 5 carries out the same analysis for the origin principle. Section 6 discusses several extensions of our basic model and Section 7 compares our results to those derived in related literature. Section 8 concludes.

\footnotetext{
${ }^{5}$ For a synthesis of different models of monopolistic competition, see Helpman and Krugman (1985, Section III; 1989, Ch. 7).
} 


\section{The model}

\subsection{Consumption}

We consider an open-economy version of the Dixit-Stiglitz-Krugman model of monopolistic competition (Dixit and Stiglitz 1977, Krugman 1979, 1980) where each variety of the differentiated good is produced using one unit of capital and a variable amount of labour (see Flam and Helpman 1987). There are two identical countries, home and foreign, the latter being denoted by an asterisk $\left(^{*}\right)$. A typical consumer in the home country maximizes the utility function $U$, which is defined over a differentiated good $D$ produced in the monopolistically competitive sector, and an outside numeraire good $C$ produced under conditions of perfect competition. All goods can be traded internationally. For the upper-tier utility function, we adopt a widely used logarithmic and quasi-linear specification (e.g. Dixit 1990: 31-34):

$$
U=\alpha \ln D+C, \quad \alpha>0 .
$$

The differentiated good $D$ consists of a large number of varieties. $D_{h}$ is the home country's per capita demand for each of $N$ domestic varieties and $D_{f}$ is the per capita demand for $N^{*}$ varieties produced abroad. Each variety is produced by one firm and varieties in each country are treated symmetrically, with $\sigma$ denoting the elasticity of substitution between any pair of differentiated goods. The substitution elasticity is restricted to be greater than unity; this ensures that a solution exists for the profit maximization problem of each firm. Hence,

$$
D=\left[N D_{h}^{\frac{\sigma-1}{\sigma}}+N^{*} D_{f}^{\frac{\sigma-1}{\sigma}}\right]^{\frac{\sigma}{\sigma-1}}, \quad \sigma>1
$$

The prices for home and foreign varieties are given by $p_{h}$ and $p_{f}$, respectively. Trade in the differentiated good is subject to transportation costs, which are captured by multiplying the prices of imported varieties by a constant $\tau>1$. In contrast to the usual specification of Samuelsonian 'iceberg' transport costs, we view transportation as a service that consumes real resources but enters the tax base of governments. ${ }^{6}$

\footnotetext{
${ }^{6}$ We thus think of transport costs in the original Von Thünen sense, who took the cost of grain transport to consist largely of the grain consumed by the horses pulling the wagon (cf. Fujita,
} 
The numeraire good $\mathrm{C}$ is freely traded, at no transport cost, and this fixes the price of this good at unity in both countries.

An ad valorem commodity tax is levied on the differentiated good under either the destination principle $\left(t_{d}\right)$ or the origin principle $\left(t_{o}\right) \cdot{ }^{7}$ Under the destination principle the home country's tax falls on the domestic consumption of all varieties of the commodity bundle $D$, whereas under the origin principle the tax falls on the domestic varieties produced for both the home and the foreign market. The commodity tax is selective in that the numeraire commodity $C$ remains untaxed. ${ }^{8}$ Denoting per capita income under the destination and origin principles by $Y_{k}, k \in\{d, o\}$, the budget constraints under the two tax regimes are given by

$$
\begin{gathered}
\left(1+t_{d}\right)\left[N p_{h} D_{h}+N^{*} \tau p_{f} D_{f}\right]+C=Y_{d}, \\
\left(1+t_{o}\right) N p_{h} D_{h}+\left(1+t_{o}^{*}\right) N^{*} \tau p_{f} D_{f}+C=Y_{o} .
\end{gathered}
$$

Introducing the dual price indices $P_{k}$, these budget constraints can be concisely written as

$$
P_{k} D+C=Y_{k} \quad \forall k \in\{d, o\}
$$

where

$$
\begin{gathered}
P_{d}=\left(1+t_{d}\right)\left[N p_{h}^{1-\sigma}+N^{*}\left(\tau p_{f}\right)^{1-\sigma}\right]^{\frac{1}{1-\sigma}}, \\
P_{o}=\left[N\left[\left(1+t_{o}\right) p_{h}\right]^{1-\sigma}+N^{*}\left[\left(1+t_{o}^{*}\right) \tau p_{f}\right]^{1-\sigma}\right]^{\frac{1}{1-\sigma}} .
\end{gathered}
$$

Maximizing (1) subject to (4) yields the demand functions for the aggregate commodity bundle $D$ and the numeraire commodity $C$. Under the quasi-linear specification of utility, all income changes affect only the demand for the numeraire good.

Krugman and Venables 1999, p. 59). If transport costs were of the strict iceberg form, no tax revenues could be collected on this service. This makes the analysis considerably more complex, as the overall level of transport costs (summed over both countries) will then be affected by tax policies. The analysis of this case is available from the authors upon request.

${ }^{7} \mathrm{Ad}$ valorem taxes are the relevant form of general commodity taxation in practice. They are also analytically convenient in the present model because they ensure that the price elasticity of demand for a variety of good $D$ is unaffected by taxes.

${ }^{8}$ This ensures that the destination and origin regimes have different real effects. If the numeraire good is also taxed at the same rate, then the two regimes are equivalent under rather general conditions, including the case of imperfect competition (Lockwood, de Meza and Myles 1994). 
Moreover, the logarithmic specification in the utility function (1) implies a unit price elasticity of aggregate demand for good $D$ in our benchmark model. ${ }^{9}$ Hence,

$$
\begin{aligned}
& D=\alpha P_{k}^{-1} \quad \forall k, \\
& C=Y_{k}-\alpha \quad \forall k .
\end{aligned}
$$

At the second stage of budgeting consumers allocate their total expenditures for the differentiated good between the different varieties. Utility maximization with respect to $D_{h}$ under the constraint of a fixed expenditure level for the bundle $D$ yields the demand for a typical domestic variety

$$
D_{h}=\left[\frac{\left(1+t_{k}\right) p_{h}}{P_{k}}\right]^{-\sigma} D=\alpha\left[\left(1+t_{k}\right) p_{h}\right]^{-\sigma} P_{k}^{\sigma-1} \quad \forall k \in\{d, o\} .
$$

Analogously, the demand for a typical variety produced abroad is

$$
D_{f}=\left[\frac{\left(1+t_{k}\right) \tau p_{f}}{P_{k}}\right]^{-\sigma} D=\alpha\left[\left(1+t_{k}\right) \tau p_{f}\right]^{-\sigma} P_{k}^{\sigma-1} \quad \forall k \in\{d, o\},
$$

where the foreign country's tax rate $t_{o}^{*}$ is relevant under the origin principle.

Substituting (6) and (7) back into (1) gives the indirect utility function

$$
V\left(t_{k}, t_{k}^{*}\right)=\alpha \ln \left(\alpha P_{k}^{-1}\right)+\left(Y_{k}-\alpha\right) \quad \forall k \in\{d, o\}
$$

which depends on tax rates in both countries.

\subsection{Production and market equilibrium}

There are $L$ identical workers in the home country and each worker inelastically supplies one unit of labour. The production of one unit of the numeraire good $C$ requires one unit of labour and no capital. These assumptions, and free trade in the numeraire good, imply a wage rate of unity in both countries. ${ }^{10}$

In the differentiated goods sector, the production of each variety, $X_{h}$, requires one unit of capital as a fixed cost. In addition, each unit of a variety of good $D$ is

\footnotetext{
${ }^{9}$ This assumption will be relaxed in Section 6 .

${ }^{10}$ Alternatively, one can assume that labour is perfectly mobile across countries (see Lockwood, 2001). In this case the price of the competitively produced numeraire commodity is fixed at unity in both countries, even if this good cannot be traded internationally.
} 
produced using one unit of labour so that variable costs are equal to unity. Including transport costs as an indirect demand, market clearing for each domestic variety of the differentiated good requires that

$$
X_{h}=L D_{h}+\tau L^{*} D_{h}^{*}
$$

where $D_{h}^{*}$ is foreign per capita demand for a domestic variety of good $D$. The profits of a typical domestic firm are given by

$$
\pi=\left(p_{h}-1\right) L D_{h}+\left(p_{h}^{*}-1\right) \tau L^{*} D_{h}^{*}-R
$$

where $\left(p_{h}-1\right)$ is the mark-up over wage costs (which equal one), $p_{h}^{*}$ is the price for a domestic variety sold abroad, and $R$ is the rate of return for the capital input.

We make the Chamberlinian large group assumption, implying that each producer perceives an elasticity of demand that is approximately equal to the elasticity of substitution between any two varieties $(\sigma)$. The profit-maximizing output price at home and abroad is identical and given by

$$
p_{h}=p_{h}^{*}=\frac{\sigma}{\sigma-1} .
$$

Eq. (12) shows that producer prices are independent of the commodity tax rates in our model, under either the destination or the origin regime. Substituting (12) back into the profit expression (11), using (8) and its foreign counterpart and $L=L^{*}$ from the assumption of identical endowments yields optimized profits $\hat{\pi}$.

Under the destination principle, the zero-profit conditions for a typical domestic and foreign firm imply

$$
\begin{gathered}
\hat{\pi}_{d}=\frac{\alpha L p_{h}^{1-\sigma}}{\sigma}\left[\left(1+t_{d}\right)^{-\sigma} P_{d}^{\sigma-1}+\left(1+t_{d}^{*}\right)^{-\sigma} \rho\left(P_{d}^{*}\right)^{\sigma-1}\right]-R=0, \\
\hat{\pi}_{d}^{*}=\frac{\alpha L p_{f}^{1-\sigma}}{\sigma}\left[\left(1+t_{d}\right)^{-\sigma} \rho P_{d}^{\sigma-1}+\left(1+t_{d}^{*}\right)^{-\sigma}\left(P_{d}^{*}\right)^{\sigma-1}\right]-R^{*}=0,
\end{gathered}
$$

where we have introduced $\rho \equiv \tau^{1-\sigma}$ for brevity, with $0<\rho<1$.

In a Chamberlinian long-run equilibrium, the rate of return to capital equals each firm's operating surplus. Capital is freely mobile internationally so that $R=R^{*}$. Furthermore, under the assumptions made about production technologies the world capital stock determines the number of firms operating in equilibrium and hence the 
total number of varieties of the differentiated good. We assume that each country is endowed with $K$ units of capital which are evenly distributed across the population. The capital market clearing condition is then given by

$$
N+N^{*}=2 K
$$

The zero-profit conditions (13)-(14) and the capital market clearing condition (15) determine the three endogenous production variables $N, N^{*}, R$. Substituting in from (5a) and the analogous equation for the price level in the foreign country, and using $p_{h}=p_{f}$ from the symmetry of the model, we obtain

$$
\begin{gathered}
N_{d}=\frac{2 K\left[\left(1+t_{d}^{*}\right)-\rho\left(1+t_{d}\right)\right]}{(1-\rho)\left[\left(1+t_{d}\right)+\left(1+t_{d}^{*}\right)\right]}, \quad N_{d}^{*}=\frac{2 K\left[\left(1+t_{d}\right)-\rho\left(1+t_{d}^{*}\right)\right]}{(1-\rho)\left[\left(1+t_{d}\right)+\left(1+t_{d}^{*}\right)\right]}, \\
R_{d}=\frac{\alpha L\left[\left(1+t_{d}\right)+\left(1+t_{d}^{*}\right)\right]}{2 \sigma K\left(1+t_{d}\right)\left(1+t_{d}^{*}\right)} .
\end{gathered}
$$

In the symmetric equilibrium with $t_{d}=t_{d}^{*}$, it is easily verified from (16) that $N=$ $N^{*}=K$. Similarly, with identical tax rates in both countries, eq. (17) reduces to

$$
R=\frac{\alpha L}{\left(1+t_{d}\right) K \sigma}
$$

Intuitively, the consumption tax raises the price level and reduces aggregate demand for the differentiated good. Since capital is employed only in this industry, its factor price must fall in equilibrium.

In Appendix A we carry out the analogous computations for the origin principle. While the expressions for the equilibrium number of firms and the return to capital are more complex under this regime, the symmetric equilibrium (with $t_{o}=t_{o}^{*}$ ) has the same properties as the symmetric equilibrium with consumption-based taxes.

Finally, we derive per-capita income $Y$ from the value of factor endowments and tax revenue, which is redistributed to the individuals as a lump sum. The income of a representative home individual, who supplies one unit of labour and $K / L$ units of capital is given by

$$
Y_{k}=1+R(K / L)+t_{k} T_{k} \quad \forall k \in\{d, o\}
$$

where $T_{k}$ denotes the per capita tax bases under the destination and origin regimes. Under the destination principle, $T_{d}$ equals per capita expenditures for $D$-goods, 
valued at producer prices

$$
T_{d}=N p_{h} D_{h}+N^{*} \tau p_{f} D_{f}=\frac{P_{d} D}{\left(1+t_{d}\right)}=\frac{\alpha}{\left(1+t_{d}\right)},
$$

where (6) has been used in the last step. Under the origin principle, $T_{o}$ equals the per capita value of domestic production

$$
T_{o}=N\left[p_{h} D_{h}+\tau p_{h}^{*} D_{h}^{*}\right]=p_{h} N \frac{X_{h}}{L}=\frac{\sigma N R}{L},
$$

where the last step has used $\pi_{h}=\left(p_{h}-1\right) X_{h}-R=0$ from (11) and (12). Note that in (20a)-(20b) we have assumed that tax revenue can be collected on the transport costs that are incurred by shipping goods abroad (see footnote 6 ).

\section{Cooperative tax policy}

Before we turn to the analysis of non-cooperative taxation, it is useful to derive the optimal cooperative tax rate as a benchmark. Given that countries are identical in our model, we can derive the cooperative tax choice by maximizing the joint welfare of the two regions, as given by the sum of indirect utilities expressed in (10) and its foreign counterpart. This ensures that tax policy internalizes all spillovers that exist between the two countries.

In our symmetric model the distinction between the destination and the origin principles is immaterial for the analysis of cooperative taxation, and both regimes must yield the same tax rate. In the following, we derive the cooperative tax rate implemented via the destination regime. ${ }^{11}$ The first-order condition for the cooperatively chosen tax rate is given by

$$
\frac{\partial V}{\partial t_{d}}+\frac{\partial V^{*}}{\partial t_{d}}=0 \Longleftrightarrow-\frac{\alpha}{P_{d}} \frac{\partial P_{d}}{\partial t_{d}}+\frac{\partial Y}{\partial t_{d}}-\frac{\alpha}{P_{d}^{*}} \frac{\partial P_{d}^{*}}{\partial t_{d}}+\frac{\partial Y^{*}}{\partial t_{d}}=0 .
$$

From symmetry, the condition for the tax rate set by the foreign country is identical. Turning first to the effects of a tax increase on the domestic and foreign price levels, we differentiate (5a) and its foreign equivalent with respect to $t_{d}$ and use $\partial N / \partial t_{d}=$

\footnotetext{
${ }^{11}$ The corresponding analysis of cooperative taxation under the origin principle is available upon request.
} 
$-\partial N^{*} / \partial t_{d}$ (since $N+N^{*}=$ const.). Further using $p_{h}=p_{f}$ and $N=N^{*}=K$ in the symmetric equilibrium gives

$$
\begin{gathered}
\frac{\partial P_{d}}{\partial t_{d}}=\frac{P_{d}}{\left(1+t_{d}\right)}-\frac{P_{d}}{(\sigma-1) N} \frac{(1-\rho)}{(1+\rho)} \frac{\partial N}{\partial t_{d}}, \\
\frac{\partial P_{d}^{*}}{\partial t_{d}}=\frac{P_{d}^{*}}{(\sigma-1) N} \frac{(1-\rho)}{(1+\rho)} \frac{\partial N}{\partial t_{d}} .
\end{gathered}
$$

The first term in (22) is the direct effect of a destination-based tax increase on the domestic price level. The remaining effects in (22) and (23) give the price level changes in the two countries induced by the relocation of firms. These are exactly offsetting so that the sum of effects in (22) and (23) equals the direct effect.

The changes in domestic and foreign income are given by differentiating (19) and its foreign equivalent with respect to $t_{d}$. This gives in a first step

$$
\frac{\partial Y_{d}}{\partial t_{d}}=\frac{K}{L} \frac{\partial R}{\partial t_{d}}+T_{d}+t_{d} \frac{\partial T_{d}}{\partial t_{d}}, \quad \frac{\partial Y_{d}^{*}}{\partial t_{d}}=\frac{K}{L} \frac{\partial R}{\partial t_{d}}+t_{d}^{*} \frac{\partial T_{d}^{*}}{\partial t_{d}} .
$$

The effects on national tax bases $T_{d}$ are obtained from (20a) and given by

$$
\frac{\partial T_{d}}{\partial t_{d}}=\frac{-\alpha}{\left(1+t_{d}\right)^{2}}, \quad \frac{\partial T_{d}^{*}}{\partial t_{d}}=0 .
$$

In the home country, an increase in the destination tax raises the consumer price of all differentiated goods and thus induces a negative demand response which reduces the tax base. In our benchmark model with logarithmic utility foreign aggregate expenditures for good $D$, and hence the foreign tax base, are unaffected by destination-based tax changes in the home country.

Finally, the change in the return to capital in both countries is derived from (17)

$$
\frac{\partial R}{\partial t_{d}}=\frac{-\alpha L}{2 K \sigma\left(1+t_{d}\right)^{2}}<0
$$

An increase in the domestic consumption tax makes the domestic market less profitable for both domestic and foreign producers, and hence reduces the worldwide rate of return to capital.

We substitute (25), (26) and (20a) into (24). Inserting the resulting expressions along with (22) and (23) into (21) and solving for the optimal coordinated tax rate $\hat{t}$ gives

$$
\hat{t}=\frac{-1}{\sigma} .
$$


The cooperatively chosen subsidy in (27) corresponds to a first-best allocation in the present model. ${ }^{12}$ The consumer price for a domestic variety of the differentiated good is $\left(1+t_{d}\right) p_{h}$. Substituting in from (12) and (27) shows that the consumer price equals unity and hence marginal cost. The price of imported varieties is $\tau\left(1+t_{d}\right) p_{f}$, which also equals total marginal costs of production and transportation. Summarizing this result gives

Proposition 1: The optimal cooperative tax policy is a subsidy at rate $1 / \sigma$. This policy achieves a first-best allocation.

Intuitively, the cooperative policy subsidizes the output of all differentiated goods with a rate that corresponds to the relative deviation of the producer price from unit costs $\left[-\left(p_{h}-1\right) / p_{h}=1 / \sigma\right.$; cf. eq. (12)]. This ensures that the price distortion arising from monopolistic competition is fully offset and an efficient allocation of consumption between the differentiated good and the numeraire good is restored. An increase in $\sigma$ reduces the mark-up charged by the monopolistically competitive firms; hence, it also reduces the need for a subsidy. In the extreme, as $\sigma \rightarrow \infty$ producers of all varieties of bundle $D$ behave in a perfectly competitive way and the optimal subsidy is zero.

Proposition 1 can be related to a result in Keen and Lahiri (1998, Proposition 2, last part) for their duopoly model with homogeneous products. According to their analysis, a first-best allocation can be achieved under both the origin and the destination basis when production efficiency requires only one firm to produce. But when preferences are of the Dixit-Stiglitz type and technologies are characterized by increasing returns to scale, then profit maximization by firms will ensure that no variety is produced by more than one firm (Helpman and Krugman 1985, Ch. 7). Therefore, in our model of monopolistic competition, cooperative tax policy under either tax regime will always lead to a Pareto efficient outcome.

The first-best optimum obtained in the cooperative case serves as a convenient benchmark to identify potential inefficiencies from non-cooperative taxation under the destination and origin principles. We now analyze the different regimes in turn.

\footnotetext{
${ }^{12}$ It is straightforward to show that the same optimal tax formula is obtained under autarky.
} 


\section{Tax competition with destination-based taxes}

We first study non-cooperative tax policy under the destination principle. The core question asked is whether national policy-makers have an incentive to pursue beggarthy-neighbour policies under this tax principle, leading to inefficient commodity tax choices in the resulting (symmetric) Nash equilibrium.

To gain an intuitive understanding for the externalities involved, we determine the effect that a domestic tax increase has on foreign welfare and evaluate this expression at the Pareto optimal tax rate $\hat{t}^{13}$ Hence we have to derive

$$
\left.\frac{\partial V^{*}}{\partial t_{d}}\right|_{t_{d}=\hat{t}}=\frac{-\alpha}{P_{d}^{*}} \frac{\partial P_{d}^{*}}{\partial t_{d}}+\frac{\partial Y^{*}}{\partial t_{d}} .
$$

This is also the marginal effect of a domestic tax change on world welfare, since nationally optimal tax policy always ensures that $\partial V / \partial t_{d}=0$. From the concavity of $\left(V+V^{*}\right)$ in $t_{d}$ we can then conclude that the non-cooperative tax rate exceeds the Pareto optimal tax rate if $\partial V^{*} / \partial t_{d}<0$ (i.e. the net spillover is negative), whereas the non-cooperative tax rate falls below the Pareto optimal tax rate if $\partial V^{*} / \partial t_{d}>0$ (the net spillover is positive).

Based on our computations in the last section, the only additional term that needs to be determined is the tax-induced change in the number of firms operating in each country. Differentiating (16) with respect to $t_{d}$ and using the symmetry of the model to simplify the resulting expression yields

$$
\frac{\partial N}{\partial t_{d}}=\frac{-K(1+\rho)}{2\left(1+t_{d}\right)(1-\rho)}<0 .
$$

This effect shows that a tax increase in the home country leads some domestic firms to leave the country and set up production abroad. ${ }^{14}$ The reason is that the domestic tax increase raises the price index of differentiated goods in the home country and makes the domestic market less profitable, relative to the foreign market. Since

\footnotetext{
${ }^{13}$ We are grateful to an anonymous referee for the suggestion to proceed in this way. A similar approach is followed in Pflüger (2001).

${ }^{14}$ It is seen from $(29)$ that $\partial N / \partial t_{d}$ is negatively related to transport costs and tends to infinity when these costs become arbitrarily small. (Note that $\rho \equiv \tau^{1-\sigma}$ tends to zero when transport costs tend to infinity, but $\rho \rightarrow 1$ when transport costs are negligible.)
} 
aggregate transport costs borne by consumers are raised when the number of foreignbased firms increases, this effect causes policy-makers to perceive an extra cost of taxation in an open economy with internationally mobile firms and costly trade.

Inserting (29) into (23) and substituting the resulting expression along with (24)(26) into (28), we obtain

$$
\left.\frac{\partial V^{*}}{\partial t_{d}}\right|_{t_{d}=\hat{t}}=\left.\frac{\alpha}{2\left(1+t_{d}\right)^{2}}\left[\frac{\left(1+t_{d}\right)}{(\sigma-1)}-\frac{1}{\sigma}\right]\right|_{t_{d}=\hat{t}}=0
$$

Hence, the non-cooperative tax rate chosen under the destination principle is firstbest, and it reproduces the optimal tax rate in the cooperative tax equilibrium! ${ }^{15}$ To interpret this surprising result we use a classification of externalities similar to that in Lockwood (2001) and distinguish between $(i)$ private consumption spillovers, (ii) public consumption spillovers, and (iii) rent spillovers. ${ }^{16}$ The first term in the squared bracket in (30) represents a positive private consumption spillover, as a tax rise in the home country will induce some firms to relocate abroad, lowering aggregate transport costs for foreign consumers [cf. eq. (29)]. The second term in the squared bracket is a negative rent spillover. It arises because a tax increase in the home country lowers the worldwide rate of return to (internationally mobile) capital and thus shifts some of the tax burden on foreign capital owners. There is no public consumption externality in our benchmark model since a tax rise under the destination principle does not affect the foreign tax base. Evaluated at the Pareto optimal tax rate $\hat{t}$, the positive private consumption spillover and the negative rent spillover exactly offset each other in their effects on foreign welfare, leaving no net strategic effect for the home country. Due to symmetry, the same is true for the foreign country.

Finally, note that both externalities present under the destination principle become

\footnotetext{
${ }^{15}$ It is straightforward to derive this result explicitly by substituting (22), (24)-(26) and (29) into$$
\frac{\partial V}{\partial t_{d}}=-\frac{\alpha}{P_{d}} \frac{\partial P_{d}}{\partial t_{d}}+\frac{\partial Y}{\partial t_{d}}=0
$$

and then solve for $t_{d}$.

${ }^{16}$ Lockwood aggregates the private and public consumption externalities into a consumer price spillover (2001: 289) and incorporates an additional producer price spillover (i.e., a terms of trade effect). The latter need not be considered here because producer prices are unaffected by taxes in our monopolistic competition model [cf. eq. (12)].
} 
weaker when the elasticity of substitution between different varieties of good $D$ is increased. In the special case where $\sigma \rightarrow \infty$, and hence the market structure approaches that of perfect competition, both externalities disappear altogether. Intuitively, if all varieties of the differentiated good are perfect substitutes, then international trade in this good ceases in the presence of transport costs, and a domestic tax increase has no effect on foreign consumer prices. Moreover, rent income is zero in the absence of a mark-up over production costs so that the rent spillover also disappears. Our results under the destination principle are summarized in

Proposition 2: The non-cooperative tax equilibrium under the destination principle is Pareto efficient and tax rates are the same as in the cooperative equilibrium. In Section 6, we will analyze whether this strong result continues to hold when countries differ with respect to population size, and when the upper-tier utility function $U(D, C)$ is generalized to allow for different values of the own-price elasticity of demand for the differentiated good.

\section{Tax competition with origin-based taxes}

Under the origin principle, the commodity tax falls on all domestically produced varieties of the differentiated good. Hence, the tax directly affects the profitability of firms in the home country. We proceed in the same way as in the previous section and determine the spillover

$$
\left.\frac{\partial V^{*}}{\partial t_{o}}\right|_{t_{o}=\hat{t}}=\frac{-\alpha}{P_{o}^{*}} \frac{\partial P_{o}^{*}}{\partial t_{o}}+\frac{K}{L} \frac{\partial R}{\partial t_{o}}+t_{o}^{*} \frac{\partial T_{o}^{*}}{\partial t_{o}} .
$$

From (5b) and its foreign equivalent, the effects of an origin-based tax change on the price levels in the two countries are given by

$$
\begin{aligned}
& \frac{\partial P_{o}}{\partial t_{o}}=\frac{P_{o}}{(1+\rho)}\left[\frac{1}{\left(1+t_{o}\right)}-\frac{(1-\rho)}{(\sigma-1) N} \frac{\partial N}{\partial t_{o}}\right], \\
& \frac{\partial P_{o}^{*}}{\partial t_{o}}=\frac{P_{o}^{*}}{(1+\rho)}\left[\frac{\rho}{\left(1+t_{o}\right)}+\frac{(1-\rho)}{(\sigma-1) N} \frac{\partial N}{\partial t_{o}}\right] .
\end{aligned}
$$

Under the origin principle, an increase in the home country's tax rate raises both the domestic and the foreign price level by a direct effect, with the weights depending 
on the proportion in which domestic varieties are consumed in the two countries. The indirect price effects caused by the relocation of firms [the second terms in (32) and (33)] are again equal and of opposite sign. Hence the sum of effects $\left(\partial P_{o} / \partial t_{o}+\right.$ $\left.\partial P_{o}^{*} / \partial t_{o}\right)$ is the same as under the destination principle.

The change in the number of firms is obtained by differentiating (A.3) in the appendix with respect to $t_{o}$. This yields

$$
\frac{\partial N}{\partial t_{o}}=\frac{-K\left[1+2 \rho(2 \sigma-1)+\rho^{2}\right]}{2\left(1+t_{o}\right)(1-\rho)^{2}}<0 .
$$

A comparison with the corresponding equation under the destination principle [eq. (29)] shows that the numerator in eq. (34) is larger and the denominator is smaller than in (29). Hence, an equiproportionate tax change leads to a larger relocation of firms under the origin regime as compared to the destination regime.

Next, the change in the return to capital under this tax regime is derived from eq. (A.4) in the appendix. It is given by

$$
\frac{\partial R}{\partial t_{o}}=\frac{-\alpha L}{2 K \sigma\left(1+t_{o}\right)^{2}}<0
$$

The effect of a tax rise on the rate of return to capital is thus the same under the origin and destination regimes [cf. eq. (26)]. This should not be surprising in a symmetric model, since the change in the worldwide return to capital is determined by the overall increase in the world price level for differentiated goods. As we have seen above, the sum of the price level effects in the two countries is the same for a given increase in either the consumption or the production tax.

Finally, the effect on the foreign country's tax base $T_{o}^{*}$ is obtained by differentiating the foreign equivalent of (20b). Using (34) and (35) gives

$$
\frac{\partial T_{o}^{*}}{\partial t_{o}}=\frac{\alpha}{\left(1+t_{o}\right)^{2}} \frac{2 \sigma \rho}{(1-\rho)^{2}}>0
$$

Eq. (36) shows that a domestic tax increase has a positive effect on the foreign tax base. This effect, which is here driven by the relocation of firms to the foreign country, parallels a well-known property of competitive models of non-cooperative commodity taxation under the origin principle (see, for example, Mintz and Tulkens 1986; Lockwood 2001, sec. 2.3). 
Substituting (34) into (33) and using the resulting expression along with (35) and (36) in (31) yields

$$
\begin{gathered}
\left.\frac{\partial V^{*}}{\partial t_{o}}\right|_{t_{o}=\hat{t}}=\left.\frac{\alpha}{2\left(1+t_{o}\right)}\left[\frac{1+2 \sigma \rho+(2 \sigma-1) \rho^{2}}{(\sigma-1)(1+\rho)(1-\rho)}-\frac{1}{\sigma\left(1+t_{o}\right)}+\frac{t_{o}^{*} 4 \sigma \rho}{\left(1+t_{o}\right)(1-\rho)^{2}}\right]\right|_{t_{o}=\hat{t}} \\
=\frac{-\alpha \sigma^{2} \rho(1+\rho)}{(\sigma-1)^{2}(1-\rho)^{2}}<0
\end{gathered}
$$

Hence, non-cooperative taxation under the origin principle leads to tax rates that exceed their Pareto efficient levels. To explain this result, we look at the three terms collected in the square bracket in (37). The first term is the private consumption spillover, which is composed of two subeffects under the origin principle. As is seen from (33), a rise in $t_{o}$ has a positive direct effect on $P_{o}^{*}$ through the increased export prices of domestically produced varieties (an effect that is absent under the destination regime), and a negative indirect effect through the relocation of firms to the foreign country. The latter effect dominates and a domestic tax increase leads to a net decrease in the foreign price level and thus a positive effect on foreign welfare. The second bracketed term in (37) is a negative rent spillover, which is due to the fall in foreign rent income. Hence, as under the destination principle, there are counteracting externalities associated with the relocation of firms on the one hand and the fall in the world interest rate on the other. Under the origin principle there is also a public consumption spillover, however, which is given by the third bracketed term in (37). This term has the same sign as $t_{o}^{*}$ and is thus negative once evaluated at the Pareto optimal subsidy $\hat{t}=-1 / \sigma$. Intuitively, the increase in the foreign tax base caused by a rise in $t_{o}$ implies that the foreign country pays out more subsidies, which partially accrue to the home economy in the form of lower consumer prices. Our model also allows to derive a closed-form solution for the optimal tax rate under the origin principle. For this purpose we have to derive the change in the home country's tax revenues following a domestic tax increase. From (20b) we obtain

$$
\frac{\partial T_{o}}{\partial t_{o}}=\frac{-\alpha}{\left(1+t_{o}\right)^{2}}\left[1+\frac{2 \sigma \rho}{(1-\rho)^{2}}\right]<0 .
$$

Substituting (32), (35) and (38) in the home country's first-order condition

$$
\frac{\partial V}{\partial t_{o}}=-\frac{\alpha}{P_{o}} \frac{\partial P_{o}}{\partial t_{o}}+\frac{K}{L} \frac{\partial R}{\partial t_{o}}+T_{o}+t_{o} \frac{\partial T_{o}}{\partial t_{o}}
$$


using $T_{o}=\alpha /\left(1+t_{o}\right)$ in the symmetric equilibrium ${ }^{17}$, and solving for $t_{o}$ gives

$$
\hat{t}_{o}=\frac{-(1-\rho)\left[(2 \sigma-1)(1-\rho)+2 \sigma^{2} \rho\right]}{\sigma\{[2 \sigma-(1-\rho)](1-\rho)+4 \sigma(\sigma-1) \rho\}}<0 .
$$

Hence, the non-cooperative tax rate chosen under the origin principle is always negative, but it is higher (i.e., the subsidy is smaller) than in the cooperative benchmark. To see this, start from a prohibitively high level of transport costs $(\tau \rightarrow \infty$ and hence $\rho \rightarrow 0)$. In this case, the origin-based tax rate replicates the cooperative tax rate $\hat{t}=-1 / \sigma$, which also equals the tax rate under autarky. In the opposite polar case of zero transport costs $(\tau=1)$, the optimal production tax is $\hat{t}_{o}=0$. More generally, differentiating (39) with respect to $\tau$ shows that the production tax rises monotonically (i.e., the subsidy becomes smaller) when transport costs are reduced. This implies that for any non-prohibitive level of transport costs the optimal production tax will exceed its Pareto efficient level.

We can again evaluate the non-cooperate tax rate under the origin principle when the market structure approaches that of perfect competition $(\sigma \rightarrow \infty)$. This implies $\rho \rightarrow 0$ and $t_{o}$ approaches the Pareto efficient level, which equals zero in this case. As under the destination regime [cf. eq. (30)] all externalities also disappear under the origin principle when commodity markets are perfectly competitive. We have already given an explanation why the private consumption and rent spillovers are zero in this case. Moreover, in the absence of a government revenue constraint the Pareto optimal tax rate is zero and hence the public consumption spillover also vanishes. This shows that the destination and origin regimes have different effects in our model only when firms have some power to set prices above marginal cost. Our results are summarized in

Proposition 3: For all finite levels of transport costs and substitution elasticities, the non-cooperative tax equilibrium under the origin principle is not Pareto efficient. Tax rates are higher (subsidies are lower) than in the cooperative equilibrium.

\footnotetext{
${ }^{17}$ This is obtained by substituting (18) and $N=K$ into (20b).
} 


\section{Extensions}

In this section we discuss some extensions of our basic model. In particular, we are concerned with the robustness of our finding that the fiscal externalities associated with international firm and capital mobility are exactly offsetting under the destination principle. First, we relax the assumption that countries are identical in all respects. A popular setting in the tax competition literature is to have countries of different 'size', which dispose of different absolute endowments of labour and capital, but have the same capital-labour ratio (see Bucovetsky 1991, Wilson 1991). It is shown in Appendix B that the Nash equilibrium tax rates under the destination principle continue to be first best in this more general framework. Intuitively, the size of the rent spillover caused by a tax change in a given country is proportional to the number of workers in this country, whereas the private consumption spillover caused by the relocation of firms is proportional to the capital endowment of the country which changes its tax rate [see eq. (A.7) in the appendix]. Therefore, if capital and labor endowments rise in the same proportion, the net effect on foreign welfare is again zero and the non-cooperative equilibrium under the destination principle continues to be Pareto efficient. ${ }^{18}$

Second, we generalize the upper-tier utility function $U(C, D)$. Our results in the previous sections have been derived under the assumption that utility is logarithmic in the consumption of the differentiated good, and hence the own-price elasticity of demand for this good is one in absolute value. A more general class of utility functions that retains the assumption of quasi-linearity is (cf. Helpman and Krugman, 1989: 141):

$$
U=\frac{\alpha \varepsilon}{(\varepsilon-1)} D^{\frac{(\varepsilon-1)}{\varepsilon}}+C
$$

\footnotetext{
${ }^{18}$ Note that the country with the larger absolute endowment of both labour and capital (say, the home country) will attract firms from the smaller country in equilibrium. This is the familiar 'home market effect' (Krugman 1980), which states that the larger market will be more profitable in the presence of transportation costs. However, even with a disproportionate number of firms located in the home country, the size of all externalities associated with a domestic tax increase depends only on the initial factor endowments of the home country.
} 
Aggregate demand for the differentiated good is then

$$
D=\alpha^{\varepsilon} P^{-\varepsilon},
$$

which implies a price elasticity of demand equal to $(-\varepsilon)$. The demand functions for domestic and foreign varieties are

$$
D_{h}=\alpha^{\varepsilon}\left[p_{h}\left(1+t_{k}\right)\right]^{-\sigma} P_{k}^{(\sigma-\varepsilon)} ; \quad D_{f}=\alpha^{\varepsilon}\left[\tau p_{f}\left(1+t_{k}\right)\right]^{-\sigma} P_{k}^{(\sigma-\varepsilon)}, \quad k \in\{d, o\},
$$

where $P_{k}$ is the price level of the differentiated good and $p=p_{h}=p_{f}$ is the profitmaximizing price chosen by domestic and foreign producers. Following Helpman and Krugman, 1989: 141) we assume that $\sigma>\varepsilon$, i.e. the substitution elasticity between any two varieties of good $D$ is larger than the overall price elasticity of demand. This ensures that the demand for an individual variety depends positively on the overall price index $P_{k}$.

For this extended model the overall effect on foreign welfare of a domestic tax change under the destination principle is derived in Appendix $\mathrm{C}$ and summarized by

$$
\left.\frac{\partial V^{*}}{\partial t_{d}}\right|_{t_{d}=\hat{t}}=\left.\frac{p^{1-\varepsilon} \varepsilon \alpha^{\varepsilon}[K(1+\rho)]^{\frac{(1-\varepsilon)}{(1-\sigma)}}}{2\left(1+t_{d}\right)^{\varepsilon+1}}\left[\frac{\left(1+t_{d}\right)}{(\sigma-\varepsilon)}-\frac{1}{\sigma}+\frac{t_{d}(\varepsilon-1)}{(\sigma-\varepsilon)}\right]\right|_{t_{d}=\hat{t}}=0 .
$$

Hence, our result that non-cooperative commodity taxation under the destination principle yields a Pareto efficient equilibrium carries over to the more general setting where the price elasticity of demand for differentiated goods is variable.

To give an intuition for this result, compare the more general expression (41) with eq. (30) derived in our benchmark setting with logarithmic utility. There are two changes. On the one hand, eq. (41) contains an additional public consumption spillover, which is given by the third term in the square bracket. This term reduces to zero in the special case where $\varepsilon=1$. Intuitively, the change in the foreign price level caused by the tax-induced relocation of firms will change aggregate foreign expenditures, and hence the foreign tax base, whenever $\varepsilon \neq 1$. If, for example, foreign demand is price elastic $(\varepsilon>1)$, then the fall in $P_{d}^{*}$ caused by a domestic tax increase will increase foreign expenditures for good $D$ and increase the foreign tax base. But since the foreign country subsidizes consumption in the optimum, the larger tax base implies a negative effect on tax revenues and hence income in the 
foreign country. This is the same effect that we have already encountered in our analysis of the origin principle (Section 5). For $\varepsilon>1$ this effect tends raise noncooperatively chosen tax rates under the destination principle above their Pareto efficient levels (subsidies are 'too low'). However, the positive private consumption spillover [the first effect in (41)] also increases if price elasticities are high. Intuitively, a high value of $\varepsilon$ leads to a large drop in the home country's demand for good $D$ following a consumption tax increase and thus causes a strong negative effect on the profitability of the domestic market. This in turn leads to a stronger relocation of firms to the foreign market and a more pronounced fall in the foreign price level for differentiated goods. It turns out that these two counteracting effects of a variation in $\varepsilon$ are exactly offsetting, so that non-cooperative tax rates under the destination principle remain at their Pareto optimal levels.

Finally, it is worthwhile to ask whether the favourable characteristics of the destination principle carry over to the monopolistic competition model of Krugman (1980), where labour is the only factor of production and the total number of firms operating in both countries is endogenous rather than fixed. Despite these changes in the model, tax policies will affect the relative profitability of the domestic and the foreign market for differentiated goods in similar ways. To be sure, the negative rent spillover operating through a reduction in the foreign country's capital income is no longer present in Krugman's setting. However, another negative externality arises from a domestic consumption tax, as the tax decreases the profitability of the home country's market and thus reduces the overall number of varieties produced. The private consumption spillovers under both the destination and origin principles are not qualitatively affected by this modification of the model. Hence the endogenous variety version of the monopolistic competition model is likely to produce qualitatively very similar results as the model analyzed above.

\section{Discussion and related literature}

The main conclusion from our analysis is that the non-cooperative tax equilibrium under the destination principle is Pareto efficient, and dominates the non-cooperative equilibrium under the origin principle (Propositions 2 and 3). Our analysis in the 
previous section has also shown that this result is robust to at least some extensions of our benchmark model. These findings are in sharp contrast to the results that Keen and Lahiri (1998, Proposition 6) have obtained in a setting of homogeneous commodities and international duopoly. In their analysis, non-cooperative taxes levied under the origin principle yield the first-best, but the same is not true if taxes are levied under the destination principle.

The explanation for this striking contrast lies in the different assumptions made about the imperfectly competitive market structure. In the homogeneous duopoly model, strategic motives are directed primarily at the distribution of firms' profits. Under the origin principle, each country has an incentive to subsidize domestic production, in order to shift profits to the domestic firm. ${ }^{19}$ This strategic motive is compatible with the goal to correct the domestic production inefficiency via a subsidy and is responsible for the Pareto optimality of origin-based commodity taxation. Under the destination principle, in contrast, a subsidy to domestic consumption will increase the profits earned by the foreign firm in the home market. Hence, strategic considerations conflict with domestic production efficiency, leading to inefficient tax rates in the non-cooperative equilibrium. For this reason, the ability to act directly on firms' output decisions is a distinct potential advantage of the origin principle in the duopoly model (Keen and Lahiri 1998, p. 343).

In our model of monopolistic competition producer prices are unaffected by taxes in equilibrium [eq. (12)] so that the entire burden of either destination- or origin-based taxes falls on consumers. Under the destination principle, the externalities associated with international firm and capital mobility are exactly offsetting so that tax policy is targeted exclusively at the domestic inefficiency resulting from imperfect competition. Under the origin principle, however, two additional spillovers are present. First, an origin-based tax falls partly on foreign consumers who cannot avoid the tax-induced increase in import prices because imported varieties are not produced domestically. Second, when production is subsidized in equilibrium, each country has an incentive to reduce the domestic subsidy as this will cause firms to locate in

\footnotetext{
${ }^{19}$ This motive is familiar from the literature on strategic trade policy (Brander and Spencer 1985). Janeba (1998) has shown, however, that the effect depends crucially on the assumption that firms cannot relocate internationally.
} 
the foreign country and thus reduces domestic subsidy payments at the expense of foreigners. These two additional motives operating under the origin principle thus work in the same direction in our model, and conflict with the goal to counteract the domestic distortion by means of a subsidy.

Finally, it is straightforward to link our results to the analysis of imperfectly competitive markets and differentiated products in Lockwood (2001, Sections 4 and 6). In Lockwood's analysis taxes levied under the destination principle cause a negative externality on the foreign country by affecting the profits of its firms. This effect corresponds to the negative spillover that destination-based taxes have in the present model on the rate of return to capital earned by foreigners. However, there is no offsetting positive externality in Lockwood's model, because firms are not allowed to relocate internationally. This is the reason why non-cooperative tax policy under the destination principle leads to a Pareto efficient allocation in the present model, but not in Lockwood's analysis. Under the origin principle, the additional negative externality on the foreign price level is also present in Lockwood's framework (and labelled a 'consumer price spillover' there). This is because the two analyses share the common assumption that goods produced at home and abroad are imperfect substitutes.

\section{Conclusions}

It is widely acknowledged that taxing international trade in the country of consumption is welfare superior to production-based taxation when commodity markets are perfectly competitive. However, as Keen and Lahiri (1998) have recently argued from a model with homogeneous products, no transport costs, and duopoly competition between firms, this ranking may be turned around in favour of the origin principle if there is imperfect competition in product markets. This caveat is important from a policy perspective because economic integration and the emergence of new technologies - the Internet, in particular - make it more costly to enforce the taxation of goods and services in the country of consumption.

In the present paper we have incorporated the policy question raised by Keen and Lahiri (1998) into an established new trade model with differentiated products, 
transport costs, and international mobility of capital and firms (Flam and Helpman, 1987). This framework incorporates a number of channels by which tax policies in one country can affect welfare in neighbouring jurisdictions, thus highlighting the potential sources for globally inefficient outcomes when tax rates are set noncooperatively. Interestingly, despite the complexity of the framework used, a rather robust case for destination-based commodity taxation has emerged from our analysis. While fiscal externalities do exist under this regime, the incentive to attract internationally mobile firms on the one hand and to tax the rents earned by foreign investors on the other tend to be offsetting - not only qualitatively, but also quantitatively. Starting from a symmetric benchmark model with logarithmic utility, we have shown that this result is robust to the introduction of differences in country 'size', and it also generalizes to utility functions that exhibit a variable own-price elasticity of demand. Under the origin principle, in contrast, there are additional externalities on the foreign tax base and on foreign import prices that lead the noncooperative tax equilibrium under this tax regime away from the Pareto efficient benchmark.

In sum, our analysis has identified a setting of imperfect competition where noncooperative taxation under the destination principle unambiguously dominates the outcome under the origin principle. This result should not be overemphasized because our analysis has maintained a number of simplifying assumptions, such as the absence of a government revenue constraint and the symmetry of countries and firms in all structural respects. At the very least, however, our monopolistic competition model with internationally mobile firms has demonstrated that the existence of imperfect competition in product markets does not lead to a general argument in favour of origin-based commodity taxes. Given the largely undisputed preference for the destination principle in perfectly competitive markets, it may then indeed be worth to accept some administrative and compliance costs in order to maintain this principle as a general scheme for taxing international trade. 


\section{Appendix}

\section{A. Market equilibrium under the origin principle}

Under the origin principle, the zero-profit conditions for a typical domestic and foreign firm are

$$
\begin{gathered}
\hat{\pi}_{o}=\frac{\alpha L p_{h}^{1-\sigma}}{\sigma}\left[\left(1+t_{o}\right)^{-\sigma} P_{o}^{\sigma-1}+\left(1+t_{o}\right)^{-\sigma} \rho\left(P_{o}^{*}\right)^{\sigma-1}\right]-R=0 . \\
\hat{\pi}_{o}^{*}=\frac{\alpha L p_{f}^{1-\sigma}}{\sigma}\left[\left(1+t_{o}^{*}\right)^{-\sigma} \rho P_{o}^{\sigma-1}+\left(1+t_{o}^{*}\right)^{-\sigma}\left(P_{o}^{*}\right)^{\sigma-1}\right]-R^{*}=0 .
\end{gathered}
$$

The zero-profit conditions (A.1)-(A.2) and the capital market clearing condition (15) are substituted in (5b) and its foreign equivalent. Introducing $\gamma \equiv\left(1+t_{o}\right)^{\sigma}\left(1+t_{o}^{*}\right)^{\sigma}$, this yields for the number of firms in the home country

$$
N_{o}=\frac{2 K\left(1+t_{o}^{*}\right)\left(1+t_{o}\right)^{\sigma}\left[\left(1+\rho^{2}\right)\left(1+t_{o}^{*}\right)^{\sigma}-2 \rho\left(1+t_{o}\right)^{\sigma}\right]}{\gamma\left(1+\rho^{2}\right)\left[\left(1+t_{o}\right)+\left(1+t_{o}^{*}\right)\right]-2 \rho\left[\left(1+t_{o}\right)\left(1+t_{o}^{*}\right)^{2 \sigma}+\left(1+t_{o}^{*}\right)\left(1+t_{o}\right)^{2 \sigma}\right]} .
$$

For the rate of return to capital under the origin principle, we get

$$
R_{o}=\frac{\alpha L\left\{\gamma\left(1+\rho^{2}\right)\left[\left(1+t_{o}\right)^{-1}+\left(1+t_{o}^{*}\right)^{-1}\right]-2 \rho\left[\left(1+t_{o}\right)^{2 \sigma-1}+\left(1+t_{o}^{*}\right)^{2 \sigma-1}\right]\right\}}{2 \sigma K\left[\left(1+t_{o}\right)^{\sigma}-\rho\left(1+t_{o}^{*}\right)^{\sigma}\right]\left[\left(1+t_{o}^{*}\right)^{\sigma}-\rho\left(1+t_{o}\right)^{\sigma}\right]} .
$$

Setting $t_{o}=t_{o}^{*}$ in (A.3) gives $N=K$, whereas (A.4) then reduces to eq. (18) in the text. 


\section{B. Differences in absolute factor endowments}

With different factor endowments in the two countries, and the destination principle in place, the firms' zero profit conditions and capital market clearing imply [cf. eqs. (13)-(15)]

$$
\begin{gathered}
R \sigma=\frac{\alpha L}{\left(1+t_{d}\right)\left(N+N^{*} \rho\right)}+\frac{\alpha \rho L^{*}}{\left(1+t_{d}^{*}\right)\left(N \rho+N^{*}\right)}, \\
R \sigma=\frac{\alpha \rho L}{\left(1+t_{d}\right)\left(N+N^{*} \rho\right)}+\frac{\alpha L^{*}}{\left(1+t_{d}^{*}\right)\left(N \rho+N^{*}\right)}, \\
N+N^{*}=K+K^{*} .
\end{gathered}
$$

For the endogenous production variables $N, N^{*}, R$, this yields

$$
\begin{gathered}
N=\frac{\left(K+K^{*}\right)\left[L\left(1+t_{d}^{*}\right)-L^{*} \rho\left(1+t_{d}\right)\right]}{(1-\rho)\left[L\left(1+t_{d}^{*}\right)+L^{*}\left(1+t_{d}\right)\right]}, \quad N^{*}=\frac{\left(K+K^{*}\right)\left[L^{*}\left(1+t_{d}\right)-L \rho\left(1+t_{d}^{*}\right)\right]}{(1-\rho)\left[L\left(1+t_{d}^{*}\right)+L^{*}\left(1+t_{d}\right)\right]} \\
R=\frac{\alpha\left[L\left(1+t_{d}^{*}\right)+L^{*}\left(1+t_{d}\right)\right]}{\sigma\left(K+K^{*}\right)\left(1+t_{d}\right)\left(1+t_{d}^{*}\right)} .
\end{gathered}
$$

The responses of the production variables to changes in the domestic and foreign tax rates are

$$
\begin{aligned}
& \frac{\partial N}{\partial t_{d}}=\frac{-L L^{*}(1+\rho)\left(1+t_{d}^{*}\right) N}{\left[L\left(1+t_{d}^{*}\right)+L^{*}\left(1+t_{d}\right)\right]\left[L\left(1+t_{d}^{*}\right)-L^{*} \rho\left(1+t_{d}\right)\right]}, \quad \frac{\partial N}{\partial t_{d}^{*}}=\frac{-\left(1+t_{d}^{*}\right)}{\left(1+t_{d}\right)} \frac{\partial N}{\partial t_{d}}, \\
& \frac{\partial R}{\partial t_{d}}=\frac{-L\left(1+t_{d}^{*}\right) R}{\left[L\left(1+t_{d}^{*}\right)+L^{*}\left(1+t_{d}\right)\right]} \frac{1}{\left(1+t_{d}\right)}, \quad \frac{\partial R}{\partial t_{d}^{*}}=\frac{-L^{*}\left(1+t_{d}\right) R}{\left[L\left(1+t_{d}^{*}\right)+L^{*}\left(1+t_{d}\right)\right]} \frac{1}{\left(1+t_{d}^{*}\right)} .
\end{aligned}
$$

The responses of the domestic price level and income are

$$
\begin{gathered}
\frac{\partial P_{d}}{\partial t_{d}}=\frac{P_{d}}{\left(1+t_{d}\right)}\left[1+\frac{L^{*}\left(1+t_{d}\right)}{(\sigma-1)\left[L\left(1+t_{d}^{*}\right)+L^{*}\left(1+t_{d}\right)\right]}\right], \\
\frac{\partial Y}{\partial t_{d}}=\frac{\alpha}{\left(1+t_{d}\right)}\left[\frac{-K}{\left(K+K^{*}\right)\left(1+t_{d}\right) \sigma}+\frac{1}{\left(1+t_{d}\right)}\right] .
\end{gathered}
$$

Substituting (A.8) in the first-order condition for the domestic tax rate, proceeding analogously for the foreign country and using $(K / L)=\left(K^{*} / L^{*}\right)$ when relative factor endowments are identical, yields the following conditions for a Nash equilibrium:

$$
\begin{aligned}
& -\left[1+\frac{1}{(\sigma-1)} \frac{\left(1+t_{d}\right)\left(L^{*} / L\right)}{\left[\left(1+t_{d}^{*}\right)+\left(L^{*} / L\right)\left(1+t_{d}\right)\right]}\right]+\left[\frac{1}{\left(1+t_{d}\right)}-\frac{1}{\left(1+t_{d}\right) \sigma\left(1+L^{*} / L\right)}\right]=0, \\
& -\left[1+\frac{1}{(\sigma-1)} \frac{\left(1+t_{d}^{*}\right)}{\left[\left(1+t_{d}^{*}\right)+\left(L^{*} / L\right)\left(1+t_{d}\right)\right]}\right]+\left[\frac{1}{\left(1+t_{d}^{*}\right)}-\frac{\left(L^{*} / L\right)}{\left(1+t_{d}^{*}\right) \sigma\left(1+L^{*} / L\right)}\right]=0 .
\end{aligned}
$$

Substituting $t_{d}=t_{d}^{*}=-1 / \sigma$ in (A.9) shows that this solves the set of equations. 


\section{Variable price elasticity of demand for differentiated goods}

We use the generalized utility function with derived demand functions (40) and proceed in the same way as in sections 3 and 4 to evaluate the net effect of a domestic tax increase on foreign welfare under the destination principle:

$$
\left.\frac{\partial V^{*}}{\partial t_{d}}\right|_{t_{d}=\hat{t}}=-\alpha^{\varepsilon} P^{-\varepsilon} \frac{\partial P_{d}^{*}}{\partial t_{d}}+\frac{K}{L} \frac{\partial R}{\partial t_{d}}+t_{d}^{*} \frac{\partial T^{*}}{\partial t_{d}} .
$$

This more general model does not allow to derive closed-form solutions for the world interest rate and the number of firms in each country. Instead, the variables $\left(N, N^{*}, R\right)$ are implicitly defined by (15) and

$$
\begin{aligned}
& R=\frac{\alpha^{\varepsilon} p^{1-\varepsilon} L}{\sigma}\left[\frac{1}{\left(1+t_{d}\right)^{\varepsilon}\left[N+N^{*} \rho\right]^{(\varepsilon-\sigma) /(1-\sigma)}}+\frac{\rho}{\left(1+t_{d}^{*}\right)^{\varepsilon}\left[N \rho+N^{*}\right]^{(\varepsilon-\sigma) /(1-\sigma)}}\right], \\
& R=\frac{\alpha^{\varepsilon} p^{1-\varepsilon} L}{\sigma}\left[\frac{\rho}{\left(1+t_{d}\right)^{\varepsilon}\left[N+N^{*} \rho\right]^{(\varepsilon-\sigma) /(1-\sigma)}}+\frac{1}{\left(1+t_{d}^{*}\right)^{\varepsilon}\left[N \rho+N^{*}\right]^{(\varepsilon-\sigma) /(1-\sigma)}}\right] .
\end{aligned}
$$

The effect of a change in $t_{d}$ on the number of firms is obtained by equating the RHS of (A.11) and (A.12) and using $N+N^{*}=$ const. This yields

$$
\frac{\partial N}{\partial t_{d}}=\frac{-\varepsilon}{2\left(1+t_{d}\right)} \frac{(1-\sigma)}{(\varepsilon-\sigma)} \frac{K(1+\rho)}{(1-\rho)} .
$$

To derive the change in $R$, we have to make use of both equations (A.11) and (A.12), since they imply different responses to a tax change. Adding up (A.11) and (A.12), differentiating with respect to $t_{d}$ and evaluating at $N=N^{*}=K$ yields

$$
\frac{\partial R}{\partial t_{d}}=\frac{-p^{1-\varepsilon} \varepsilon \alpha^{\varepsilon} L(1+\rho)}{2 \sigma\left(1+t_{d}\right)^{\varepsilon+1}[K(1+\rho)]^{(\varepsilon-\sigma) /(1-\sigma)}} .
$$

The effects on the foreign price level $P_{d}^{*}$ and the foreign tax base $T_{d}^{*}=P_{d}^{*} D^{*} /\left(1+t_{d}^{*}\right)$ are given by

$$
\begin{gathered}
\frac{\partial P_{d}^{*}}{\partial t_{d}}=\frac{-P_{d}^{*}}{2\left(1+t_{d}\right)} \frac{\varepsilon}{(\sigma-\varepsilon)}, \\
\frac{\partial T_{d}^{*}}{\partial t_{d}}=\frac{p^{1-\varepsilon} \varepsilon \alpha^{\varepsilon}}{2\left(1+t_{d}\right)^{\varepsilon+1}(\sigma-\varepsilon)}[K(1+\rho)]^{\left(\frac{1-\varepsilon)}{1-\sigma)}\right.}[-1+\varepsilon] .
\end{gathered}
$$

It is easily checked that for $\varepsilon=1$ the expressions in (A.13)-(A.15) reduce to their respective values in the main text [see eqs. (23), (25), (26) and (29)].

Substituting (A.13), (A.14) and (A.15) into (A.10), using $P_{d}^{*}=\left(1+t_{d}^{*}\right) p[K(1+$ $\rho)]^{1 /(1-\sigma)}$ and evaluating at $t_{d}=\hat{t}=-1 / \sigma$ yields equation (41) in the main text. 


\section{References}

Andersson, F. and R. Forslid (1999), Tax competition and economic geography. CEPR Discussion Paper No. 2220. Centre for Economic Policy Research, London.

Baldwin, R. and P. Krugman (2000), Agglomeration, integration, and tax harmonization. CEPR Discussion Paper No. 2630. Centre for Economic Policy Research, London.

Brander, J.A. and B. Spencer (1985), Export subsidies and international market share rivalry. Journal of International Economics 18, 83-100.

Bucovetsky, S. (1991), Asymmetric tax competition. Journal of Urban Economics 30, 167-181.

Dixit, A. (1990), Optimization in economic theory, Second edition. Oxford University Press.

Dixit, A. and J.E. Stiglitz (1977), Monopolistic competition and optimum product diversity. American Economic Review 67, 297-308.

Flam, H. and E. Helpman (1987), Industrial policy under monopolistic competition. Journal of International Economics 22, 79-102.

Frenkel, J., A. Razin and E. Sadka (1991), International taxation in an integrated world. MIT Press, Cambridge (Mass.).

Fujita, M., P. Krugman and A. J. Venables (1999), The spatial economy. Cities, regions, and international trade. MIT Press, Cambridge (Mass.) and London.

Goolsbee, A., 2000, In a world without borders: The impact of taxes on Internet commerce. Quarterly Journal of Economics 115, 561-576.

Haufler, A., G. Schjelderup and F. Stähler (2002), Economic integration and the choice of commodity tax base under imperfect competition. Mimeo.

Helpman, E. and P. Krugman (1985), Market structure and foreign trade. MIT Press, Cambridge (Mass.). 
Helpman, E. and P. Krugman (1989), Trade policy and market structure. MIT Press, Cambridge (Mass.).

Janeba, E. (1998), Tax competition in imperfectly competitive markets. Journal of International Economics 44, 134-153.

Keen, M. and S. Lahiri (1998), The comparison between destination and origin principles under imperfect competition. Journal of International Economics 45, 323-350.

Keen, M. and S. Smith (1996), The future of value-added tax in the European Union. Economic Policy 23, 375-420.

Keen, M. and D. Wildasin (2000), Pareto efficiency in international taxation. CESifo Working Paper 371. University of Munich.

Kind, H.J., K.H. Midelfart Knarvik and G. Schjelderup (2000), Competing for capital in a "lumpy" world. Journal of Public Economics 78, 253-274.

Krugman, P. (1979), Increasing returns, monopolistic competition, and international trade. Journal of International Economics 9, 469-479.

Krugman, P. (1980), Scale economies, product differentiation, and the pattern of trade. American Economic Review 70, 950-959.

Lockwood, B. (1993), Commodity tax competition under destination and origin principles. Journal of Public Economics 53, 141-162.

Lockwood, B. (2001), Tax competition and tax co-ordination under destination and origin principles: a synthesis. Journal of Public Economics 81, 279-319.

Lockwood, B., D. de Meza and G. Myles (1994), When are origin and destination regimes equivalent? International Tax and Public Finance 1, 5-24.

Ludema, R.L. and I. Wooton (2000), Economic geography and the fiscal effects of regional integration. Journal of International Economics 52, 331-357.

Martin, P. and C.A. Rogers (1995a), Industrial location and public infrastructure. Journal of International Economics 39, 335-351. 
Martin, P. and C.A. Rogers (1995b), Trade effects of regional aid, in: R. Baldwin, P. Haaparanta and J. Kiander (eds.), Expanding membership of the European Union. Cambridge University Press, 166-188.

Mikesell, J.L. (2000), Remote vendors and American sales and use taxation: The balance between fixing the problem and fixing the tax. National Tax Journal 53, 1273-1285.

Mintz, J. and H. Tulkens (1986), Commodity tax competition between member states of a federation: Equilibrium and efficiency. Journal of Public Economics 29, 133-172.

Nam, C.W., R. Parsche and B. Schaden (2001), Measurement of value added tax evasion in selected EU countries on the basis of national accounts data. CESifo Working Paper 431. University of Munich.

Pflüger, M. (2001), Ecological dumping under monopolistic competition. Scandinavian Journal of Economics 103, 689-706.

Venables, A. (1987), Trade and trade policy with differentiated products: A Chamberlinian-Ricardian model. The Economic Journal 97, 700-717.

Wilson, J.D. (1991), Tax competition with interregional differences in factor endowments. Regional Science and Urban Economics 21, 423-451. 